
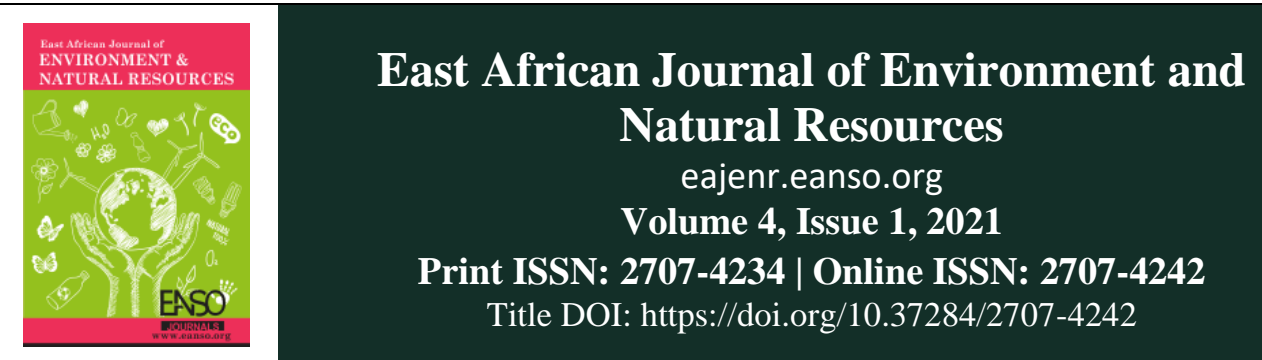

Original Article

\title{
Dimensions of Urban Park Use in Nairobi County in Kenya.
}

\author{
Mathias Loki Mutisya ${ }^{1 *}$ \\ ${ }^{1}$ Jomo Kenyatta University of Agriculture and Technology, P. O. Box 62,000-00200 Nairobi, Kenya. \\ ${ }^{*}$ Correspondence ORCID ID: https://orcid.org/0000-0003-0826-787X, email: mmutisya@jkuat.ac.ke
}

Article DOI: https://doi.org/10.37284/eajenr.4.1.448

\section{Date Published: ABSTRACT}

26 October 2021 Urban parks play an integral part in the social, economic, and environmental wellbeing of the society they serve. Apart from their aesthetic value, they are a

Keywords: source of income, help in the purification of air, as well as being set for both

Urban Parks, studies, it has been established that some of these parks either sometimes fail to

Park Use, serve their intended purpose while others fail in some aspects. This study,

Green Spaces, therefore, aims to investigate the general usage of the six gazetted urban parks in

Dimensions, Nairobi County. Through the review of relevant literature, visitation trends,

Park Users. location, diversity of activities, gender, and duration of stay were found to be key determinants of the way the parks are used. A sample size of 243 convex spaces, was used for the study. Interviews and observation methods were used to gather relevant information on the use of the park spaces while data collection tools used included observation schedules, checklists, and photography. Thereafter, descriptive and correlation methods were used in the collected data analysis. The study found out that majority of urban park users were male and mostly those self-employed or jobless. The frequency of park visits was greatly affected by lack of time to visit and understanding of various benefits associated with park visits. Visitors preferred visiting with friends or in groups and stated relaxation as the main reason for visiting the parks.

\section{APA CITATION}

Mutisya, M. L. (2021). Dimensions of Urban Park Use in Nairobi County in Kenya. East African Journal of Environment and Natural Resources, 4(1), 15-24. https://doi.org/10.37284/eajenr .4.1.448

\section{CHICAGO CITATION}

Mutisya, Mathias Loki. 2021. "Dimensions of Urban Park Use in Nairobi County in Kenya". East African Journal of Environment and Natural Resources 4 (1), 15-24. https://doi.org/10.37284/eajenr.4.1.448.

15 | This work is licensed under a Creative Commons Attribution 4.0 International License. 


\section{HARVARD CITATION}

Mutisya, M. L. (2021) "Dimensions of Urban Park Use in Nairobi County in Kenya", East African Journal of Environment and Natural Resources, 4(1), pp. 15-24. doi: 10.37284/eajenr.4.1.448.

\section{IEEE CITATION}

M. L. Mutisya, "Dimensions of Urban Park Use in Nairobi County in Kenya", EAJENR, vol. 4, no. 1, pp. 15-24, Oct 2021.

\section{MLA CITATION}

Mutisya, Mathias Loki. "Dimensions of Urban Park Use in Nairobi County in Kenya". East African Journal of Environment and Natural Resources, Vol. 4, no. 1, Oct 2021, pp. 15-24, doi:10.37284/eajenr.4.1.448.

\section{INTRODUCTION}

With an estimated $70 \%$ of the world's population expected to be living in the urban areas by 2050 (the UN-Habitat, 2010), overcrowding, pollution, and high demand for public open spaces are going to be a challenge that any municipality shall have to deal with. Demand for more space to build will also be high, exposing public open space to the danger of encroachment for development. Urban parks form part of these public open spaces and proper policy and protection measures need to be put in place to ensure that society benefits from the crucial role they play. Many cities face challenges associated with congestion and pollution due to increased population and this is not likely to change. People in urban areas visit parks for various reasons ranging from relaxation, socialization, exercise to just enjoying the views and a breath of fresh air. For effective use of the parks and open spaces they offer, user needs, quality of physical features therewithin and spatial structure form the main aspects that need to be considered during planning, creation, rehabilitation, and maintenance of the parks. According to Beck (2009), the quality of the physical features of the open space improves people's satisfaction and quality of life, promoting better use (Gehl, 1987) while enhancing the social, environmental, and economic values.

Urban parks exist in different sizes and settings, with most scholars classifying them according to their location, function, and size. Saika \& Kikuchi (2017), classify them according to their character, purpose and size. The study was conducted within the six gazetted urban parks within Nairobi County, Kenya which include Jevanjee gardens, City Park, Uhuru Park, Uhuru Gardens, Nairobi Arboretum, and Central Park. The study aimed to investigate the general aspects of the usage of the six urban parks. The usage aspects relate both to the users and the physical settings of parks. They include the user gender, reasons for visit, location of the park, activities therewithin, frequency of visit, and the level of participation. The target population for the study was the convex spaces within the six parks which included both the access routes into and within the park and the sub-spaces therein. The study's unit of analysis was the convex space and park users from the six urban parks.

\section{LITERATURE REVIEW}

\section{Urban Parks: Definition and Classification}

Urban parks are defined as delineated open space areas, mostly dominated by vegetation and water, and generally reserved for public use. They are mostly larger, but can also have the shape of smaller pocket parks. Most scholars classify them according to their location, function, and size. Saika \& Kikuchi (2017), classify them according to their character, purpose and size. Solecki (1995), describes parks as urban landscapes which serve many functions such as the provision of environmental benefits, active and passive recreations, and serving as wildlife habitats.

\section{Why Do People Visit Urban Parks?}

According to Gavin et al. (2010), parks are essential for human health and physical activity. People visit parks for a range of activities and experiences. An effective green open space will cater to a diverse range of physical activities and uses. Physical activities are classified according to Kellet (2009) as passive ones, often referred to as inactive behaviour, moderate activities such as walking, or vigorous activities such as running and playing team sports. Others visit parks just for refreshments as observed by Deister (2013) in a study carried out at Al Rehab city, Cairo. Parks form part of natural settings in our urban areas and as Ulrich et al. (1991) assert, nature supports human wellbeing by facilitating stress 
reduction. People will often visit parks to relax and have peace of mind away from their daily work. Urban parks also have the potential to facilitate social interaction and even encourage social cohesion for people from a variety of ethnicities (Peters et al., 2010).

\section{Urban Park User Age and Gender}

Parks are considered important for public mental health and provide them opportunities to enhance the value of life for people of all age groups and abilities (Cohen et al., 2006). Research has shown that various age groups and gender have different interests in visiting parks. It has gone further to explore the impact of gender and age on visiting parks. According to Hayward (1989), they serve the needs and interests of all groups of people of a community: young or old, groups or individuals, male or female. It has been established that younger people throughout the world are attracted to more active activities and interactive play with landscape features, while adults and the elderly are more likely to enjoy nature opportunities that afford contemplation (Kaptan, 2008).

\section{Attributes Associated with Park Use}

The way an urban park is used or visited varies from one locality or municipality to another as well as from one visitor to another. This is due to different physical attributes of the parks as well as visitor preference, social status, gender, and age.

\section{Accessibility}

Accessibility is one of the most important concerns in observing the trend of the population visiting urban parks because it highly depends on the spatial distribution of urban parks in any region (Zhang, 2011). Kellet (2009) describes accessibility as the ability of an individual to reach a specific green space while McCormack (2010) suggests that open green spaces that are accessed within a walking distance are most likely to attract more users. This implies that the longer the distance to the open space the lesser the preference as it might require one to drive or use motorized means of transport. The more proximate a public green space is, the higher physical activity is said to include (Cohen, 2007). In other studies, distance is often mentioned as the main environmental factor influencing the use of green space (Coles and Bussey 2000; Van Herzele and Wiedemann 2003; Giles-Corti et al., 2005), and a distance of 300 to $400 \mathrm{~m}$ is seen as a typical threshold value after which the use frequency starts to decline (Grahn and Stigsdotter, 2003). If parks are located at a place where most people cannot access them, they are usually devoid of many physical and social activities (Ottensmann, 2008).

\section{Safety}

Safety is described as the condition of being protected from or unlikely to cause danger, risk, or injury. Parks should offer safety to the users irrespective of their gender and age. A study by Babey (2008) deduced that the use of safe parks is relatively high compared to unsafe ones. According to McCormack (2010), some park users, especially women would rather not visit parks if they felt unsafe however close they were from their areas of residence. Safety in parks can be achieved in various ways and as Baum, (2002) found out, vegetation in open green spaces can provide a cover for persons involved in illegal activities thus resulting in reduced use of public green spaces.

\section{Features and Amenities}

Features and amenities found in parks highly affect the usage and these effects could either be

negative or positive. Studies show that access to green spaces that contain a variety of activities for children and adolescents is relatively high, while McCormack (2010) found that for adults, constructed and natural trails were important. McCormack (2010) further asserts that other amenities such as barbeques, seating, water fountains, picnic tables, shading devices, and bathrooms play an important role in access to those spaces regardless of age.

\section{METHODOLOGY}

17 | This work is licensed under a Creative Commons Attribution 4.0 International License. 


\section{Introduction}

The study was conducted within the six gazetted urban parks within Nairobi City which include the Jevanjee Gardens, City Park, Uhuru Park, Uhuru Gardens, Nairobi Arboretum, and Central Park. The target population for the study was the convex spaces within the six parks which included both the access routes into and within the park and the subspaces therein. The study's unit of analysis was the convex space and park users from the six urban parks.

\section{Data collection, Type, and Methods}

Primary data constituted first-hand field data collected from the sample size of 243-unit spaces/park users from the six urban parks. The nature of data collected included user characteristics, user's company to the space, the average duration of visit, the purpose of visit, level of participation, the intensity of space use, and vehicular use patterns.

The study employed two major methods of data collection namely; the observation method and interviews. Observation schedules and checklists were used as a guide to gathering relevant information for the variables mentioned above. Instruments used included tally counters and cameras. Other related techniques integrated by the study included behaviour mapping to capture the user behaviour in the space. Information collected was entered on the observation schedules and checklist. Structured interview schedules were used to gather data under three major sections; space code and researcher's details; respondent details; and park utilization trends.

\section{Procedure}

This was a descriptive study of the six parks and focused on the convex spaces and users. Observation and interview schedules were administered to users in the sampled 243 convex spaces. Proportionate sampling was then used to determine the sample size per park since the study area comprised several parks that are different in number in terms of convex spaces. The number of convex spaces from each park was determined by their number relative to the entire population. Using the standardized random tables as recommended by
Mugenda and Mugenda (2003), the study applied a simple random sampling technique in sampling representative samples out of the overall sample size of 243 convex spaces. On the other hand, systematic sampling was used to sample respondents by taking every second respondent visiting a sampled space after the researcher arrives in the space.

Study maps generated for the six parks with clearly defined convex spaces were used by the researcher to gather information through direct observation and interviews along with the study variables. One observation schedule per convex space was administered capturing information under each variable. The observation schedules were structured to collect information on utilization trends under the following areas; type of activities in space, diversity of activities, number of participants, user's level of participation in activities, gender diversity, and vehicular use patterns. Structured interview schedules on the other hand were designed to gather information on the following areas; space code, respondent's bio-data, respondent's accessibility details to the space such as mode of transport, distance, time taken, and respondent's opinion on security in the space. An on-site participation approach was applied in completing the interview schedules.

\section{Variable and Measures}

The construct of frequency of visit (FV) was taken to be how often the respondents visited the space in a year. These data were collected through interviews and entered on the schedules. The number of times the respondent visits were then categorized and measured in a 5-point Likert - scale where 1 represented once in a year, 2 represented not more than twice in a year, 3 represented occasionallyevery month but not every week, 4 represented frequently at least once in a week and 5 represented always more than thrice a week.

The average number of people visiting (PV) on the other hand was measured as the number of people the respondents visit the park with. This construct was grouped and measured on a 5-point Likert scale, such that those who visit the park alone was coded as 1 , one who visits with one friend was taken to be 2 , one who visits in a group of 2-5 people was 
taken to be 3, those who visit in a group of 5-10 people were taken to be 4 while those visiting in a large group of more than 10 people were taken to be 5. This information was collected through interviews.

The study defined the construct of average duration of stay (DS) as the approximate time one stays in the park. On a 5-point Likert - scale, less than an hour was coded to be 1 , not more than an hour was taken to be 2, not more than 2 hours was taken to be 3 , not more than 3 hours was taken to be 4 while more than 3 hours was taken to be 5 . Use of space (US) as a construct was taken to be the opinion of the respondent on whether the space is used for the right purpose or not. This construct was measured on a 5-point Likert scale where 1 was strongly disagree and 5 was strongly agree.

The construct of the level of participation (LP) was defined as the respondent's level of participation in active recreational activities in the space whenever they visited. The respondents rated these on a 5point Likert scale where 1 was not active while 5 were extremely active. The diversity of activities in the park (DA) was measured using the observation method. On an observation schedule, the researcher documented the activities present in a space under 7 categories namely; passive stationary recreational activities, social recreational activities, active transport, active stationary recreational activities, active mobile recreational activities, economic activities, and spiritual activities. A summary of the total number of activity types in space was then calculated. The number of activities per square meter was then calculated.

The intensity of use (IU) was taken to be the overall density of participants in space. This was gotten through the observation method by documenting the total number of participants per activity in space. The number of participants per square meter was then calculated. The construct of gender disparity (GD) was measured by documenting both the total number of females and males in space and calculating the density per square metre. Vehicular use patterns (VP) were taken to be the density of vehicles using the space. The total number of parked and mobile vehicles in space was documented and the density per square metre was calculated.

\section{RESULTS FINDINGS}

\section{Demographic Characteristics}

Table 1 below shows a summary of demographic characteristics for the respondents. These characteristics included: Respondent's gender, marital status, age, level of formal education, employment status, Nationality, homeownership status, and the duration of stay in the neighbourhood.

Table 1: Demographic Characteristics

\begin{tabular}{llll}
\hline & & Frequency & Percent \\
\hline \multirow{3}{*}{ Gender } & Male & 173 & 72.1 \\
& Female & 67 & 27.9 \\
& Total & 240 & 100.0 \\
\hline \multirow{4}{*}{ Marital Status } & Married & 162 & 67.5 \\
& Single & 75 & 31.3 \\
& Widow & 2 & .8 \\
& Widower & 1 & .4 \\
Age & Total & 240 & 100.0 \\
\hline \multirow{3}{*}{ Less than 11 yrs. } & 1 & .4 \\
& $12-17$ yrs. & 1 & .4 \\
& $18-55$ yrs. & 228 & 95.0 \\
& 55 yrs. and above & 10 & 4.2 \\
& Total & 240 & 100.0 \\
\hline
\end{tabular}

19 | This work is licensed under a Creative Commons Attribution 4.0 International License. 
East African Journal of Environment and Natural Resources, Volume 4, Issue 1, 2021

Article DOI: https://doi.org/10.37284/eajenr.4.1.448

\begin{tabular}{|c|c|c|c|}
\hline & & Frequency & Percent \\
\hline & College & 101 & 42.3 \\
\hline & Total & 239 & 100.0 \\
\hline & Employed & 97 & 40.6 \\
\hline Fmplovment status & Self-employed & 106 & 44.4 \\
\hline Empioyment status & Unemployed & 36 & 15.1 \\
\hline & Total & 239 & 100.0 \\
\hline & Kenyan & 235 & 97.9 \\
\hline Nationality & Foreigner & 5 & 2.1 \\
\hline & Total & 240 & 100.0 \\
\hline & Rental & 212 & 89.1 \\
\hline Homeownership & Owner-occupier & 26 & 10.9 \\
\hline & Total & 238 & 100.0 \\
\hline & $<5$ years & 116 & 48.7 \\
\hline Duration of stay $i$ & $5-9$ years & 67 & 28.2 \\
\hline Duration of stay it & the $10-20$ years & 38 & 16.0 \\
\hline & $>20$ years & 17 & 7.1 \\
\hline & Total & 238 & 100.0 \\
\hline
\end{tabular}

Results in Table 1 reveal that out of the surveyed respondents, park visitation was more skewed towards males (72\%) than females (28\%). The majority of the park users were married $(68 \%)$ the least being widows and widowers $(2 \%, 1 \%)$ respectively. The youth and middle-aged (18-55 years) frequented the parks most (95\%) and had a higher level of formal education at the college level $(42 \%)$. The majority of space users were also selfemployed (44\%) and were Kenyan citizens (98\%) living in rental houses $(89 \%)$ in neighbourhoods where they have lived for less than 5 years (49\%).
Results indicated that the majority of space users are self-employed $44 \%$ and live in rental houses $89 \%$ having lived in their estates for less than 5 years on average. Congestion, inadequate or lack of public spaces, and basic quality services such as fresh air and natural settings in most residential places could be a contributing factor to the high percentage of patronage to park spaces within Nairobi County by the middle class.

\section{Table 2: Descriptive Statistics of the indicators of Park Utilization}

\begin{tabular}{lllll}
\hline & Minimum & Maximum & Mean & Std. Dev. \\
\hline Frequency of Visit & 1.00 & 365.00 & 161.71 & 134.68 \\
Average number of people visiting & 1.00 & 800.00 & 12.42 & 89.07 \\
Duration of Stay in a Space & 0.08 & 30.00 & 5.28 & 5.11 \\
Purpose of space visitation & 1.00 & 5.00 & 3.91 & .649 \\
Level of participation in active recreation & 1.00 & 5.00 & 2.14 & 1.13 \\
Diversity of Activities in the Space & .00 & 10.53 & .729 & 1.34 \\
Intensity of use & .00 & 176.92 & 5.18 & 13.75 \\
Gender Disparity & .00 & 176.92 & 5.08 & 13.53 \\
Vehicular use patterns & .00 & 30.43 & .672 & 3.11 \\
Park Utilization & 1.67 & 4.22 & 2.82 & .517 \\
\hline
\end{tabular}

From Table 2, results revealed that park spaces were frequently visited. Results revealed that out of 365 days in a year, park spaces were visited 162 times on average $(M=161.71, S D=134.68)$. The standard deviation is high at 134.68 indicating a high variance of values from the mean and the visitors were in a group of 12 on average $(M=$ $12.42, S D=89.07)$. The visitors to park space spent 
approximately 5 hours during their park visits $(M=$ $5.28, S D=5.11)$, and in their opinion, they agreed that the park was used for the right purpose $(M=$ 3.91, $S D=0.649$ ). The visitors rated their participation level in active recreational activities in the space during their visits as least active $(M=$ $2.11, S D=1.13)$. The respondents were asked to indicate the number of activities carried out in the space per $\mathrm{M}^{2}$ and was found to be $0.729 \%$ on average with a standard deviation of 1.34 . The intensity of use indicated by the density of participants was found to be $5.18 \%$ on average, Gender disparity indicated by Gender density in space use was found to be $5.08 \%$ on average and a standard deviation of 13.53. Vehicular use patterns indicated by the density of vehicles using the space were found to be $0.672 \%$ on average and a standard deviation of 3.11 per square metre.

Finally, a total score of the indicator variables was obtained to form a variable called Park Utilization (dependent variable). A score of 1 indicated that the Park Space was least utilized while a score of 5 indicated that the Space was most utilized. The results indicated that the Park Spaces were somewhat utilized as indicated by a mean value of 2.82 and a standard deviation of 0.517 .

\section{DISCUSSION OF RESULTS}

\section{Frequency of Visits in Parks}

Results revealed that out of 365 days in a year, space users visited 162 times on average. A standard deviation of 134.7 could be attributed to the diverse reasons for visiting the spaces. A low entry (Min. 1.00 ) could be linked to those found to visit once for reasons not planned for such as waiting to be picked up by a colleague on their first-time visit to the city or waiting for an appointment. Users recording a daily visit (Max. 365.00) to the park were found to be business people located in the spaces. Another category of daily visitors to the park spaces established by the study included the vagrants and the homeless persons, who treated the parks as homes and places of idling. Reasons given by space users for rarely visiting the spaces were lack of time and knowledge on the importance of recreation in their daily lives.

\section{Average Number of People Visiting}

Results indicated that an average of 12 persons visited the spaces per group per visit. A high standard deviation of 89.07 could be attributed to the diversity of group sets visiting the park spaces for varied reasons. Reasons for visiting in groups ranged from personal quiet time, attending group activities, socialization with friends, and security reasons. A low entry of 1 person per visit may be associated with those visiting the space for their reasons such as for meditation and quiet time, praying, and the jobless. The tendency to visit in groups could be associated with several factors such as; engagement in group activities such as picnicking with friends, prayer retreats as noticed at Nairobi Arboretum, politicking mostly documented in Jeevanjee Gardens, and school games. Also, security could be linked with group visits as young children were accompanied by parents or guardians. A high entry of (Max. 800.00) could be linked to school visits, for games and recreation as witnessed in Uhuru Gardens and Uhuru Park.

\section{Duration of Stay in a Space}

Study findings revealed that space visitors spent approximately 5 hours during their park visits. Such duration could be explained by the categories of visitors found in space. The self-employed category of users recorded the highest percentage (44\%) as shown in Table 1 were business people, the jobless and those visiting in groups recorded a longer period of stay in the spaces. While business people stayed in the spaces the whole day, the jobless were found to have turned the open spaces into homes and places to get handouts from other space visitors. Illegal activities were associated with this category of the group such as smoking, drinking, robbery, rape, and stealing. Such engagement in illegal activities could be an indicator of the absence or low visit rates by some categories of groups such as women recording just a $28 \%$ response rate as indicated in Table 1. Reasons for less time in the parks were attributed to a lack of enough time by the respondents.

\section{Purpose of Space Visitation}

Respondent's opinion on whether spaces were rightfully used or not revealed that they were used 
for the right purpose on average $(M=3.91)$. Activities documented in the parks included sleeping, sitting, socialization, playing, preaching, praying, meetings, recreational walking and jogging, hawking, vending, photography and boating. The presence of police patrols enhanced security in the spaces hence reduction in illegal activities and crime rates in the majority of the spaces.

\section{Level of Participation in Active Recreation}

Study findings revealed the least engagement in active recreation in the park spaces $(M=2.11)$. Even though the study documented a wide variety of activities in the spaces, ranging from passive to active, it was noted that the most dominant activity was passive activities such as sitting and sleeping. This could be linked to inadequate park equipment which translates to monotony of activities and boredom. It was also established that the type of material in the spaces supported passive activities such as sleeping and sitting. The majority of space users were found comfortable sitting and sleeping on lawns and under the trees for shade. In addition, the purpose of the visit could be an indicator of the type of activity a user engages in. Findings revealed that the majority visited the spaces for personal reasons that go with passive engagement such as meditation, relaxing, sleeping especially for security guards as they await a change of work shift and the homeless who treated the spaces like homes and places of sleeping.

\section{Diversity of Activities in the Space}

Results revealed a wide variety of activities in the spaces. Seven categories of activities were documented as detailed below:

- Passive stationary recreational activities such as sitting, sleeping, standing, reading, relaxing, and eating were observed. The lawn was observed as the most preferred activity location for these categories of activities.

- Social recreational activities included group meetings and organised plays. Varied group sizes ranging from two to over forty were documented. Diverse categories of users were also reported ranging from couples, friends, businessmen to corporate meetings. Reasons for such meetings included bonding and relaxing, political discussions, business dealings, team building, and prayer groups. Different parks were characterised by specific activities as most business and political meetings were found in Jeevanjee gardens, Uhuru Park, City Park, and Uhuru Gardens. The majority of personalised and specific social and spiritual activities were mostly reported in parks that present a quiet and conducive natural setting for such activities, such as City Park and Nairobi Arboretum. Activity type, convenience, and ease in accessibility were found to be driving forces in the choice of the park and space to visit.

- Active mobile recreational activities such as recreational walking and jogging were reported in City Park and Nairobi Arboretum. The natural forests and presence of nature trails were found to be contributing factors to the location of these two activities.

- Economic activities found in the study spaces included hawking, vending, kiosk managing, photography, and private play equipment, businessmen. Hawking, vending, and photography were reportedly the dominant economic activities in the six urban parks. It was observed that the parks lacked designated points for such activities which were found to cause congestion and conflict in activity engagement and movement, especially during peak hours. Space users were observed not to be comfortable with activities such as hawking.

- Spiritual activities reported by the study included preaching, praying, and meditation in the spaces. Easily accessible parks that are close to the town centre reported preaching activities as they registered large numbers of visitors during lunchtime hour break. Such parks include Jeevanjee gardens, Uhuru Park and City Park. The quiet time involving bible study and individual prayers was mostly reported in less noisy and congested Parks such as Nairobi Arboretum and City Park. Specifically, it was found to happen near spaces that offer some degree of privacy such as near the forests. Prayer group retreats were documented only in City Park and Nairobi Arboretum. 


\section{The intensity of Space Use}

The study reported a relatively low intensity of space use $(M=5.18 \%$, SD 13.75$)$ as indicated by the density of participants in a space. Results in table 5.2.2 reveal that some spaces reported zero participants while others were overpopulated (Min=0, Max=176.92). This disparity in space use could be linked to a wide range of factors ranging from spatial to related space utilization trends such as the category of space users, conflicting activities, security, and park features.

\section{Gender Disparity}

The study reported a huge gender disparity representation in the spaces, the majority being male posting $72 \%$ compared to female at $28 \%$ as indicated in table 1 . This could be linked to issues of privacy in women as culturally women are believed to stay longer in their homes. Comfort and security could also have a bearing on gender representation. Activities engaged in the parks also dictate the gender present in the spaces. For example, in Jeevanjee Gardens, a large grouping of political discussions could scare away women. The presence of the homeless in the spaces could also create perceptions of fear in women; hence they would avoid the spaces.

\section{Vehicular use Patterns}

Results revealed a high percentage of intensity of vehicles per square metre $67 \%$ in the spaces as shown in table 1 . The use of roads traversing park spaces such as Uhuru Park and City Park could have an implication to the high percentage. In Uhuru Park, vehicles traversed through the Processional Way in high numbers, especially during peak hours. Other vehicles belonging to park users were found parked in the parking lots and along the roads. City Park Road that leads to City Park residential houses and also connecting to Thika superhighway was found to attract a high number of mobile vehicles. Stationary vehicles were few based on the size of the parking lot. The mode of transport to the park varied across different parks as over $90 \%$ of space users in Uhuru Gardens accessed the park through private vehicles. Proximity from the $\mathrm{CBD}$, the type of activity undertaken and the category of space user was found as a key determinant of the mode of transport used. Minimal designated parking lots were reported in all the parks resulting in the parking of vehicles anywhere on the lawn at the user's convenience. Generally, it was observed that only three parks out of six allowed entries of vehicles. These were Uhuru Park, City Park, and Uhuru Gardens, the rest strictly allowed walking into the park.

\section{CONCLUSION}

The study adds to the rapidly expanding body of research on urban parks usage by examining their various dimensions in visitors' gender, activity variety, location, the reason for visit, space intensity, means of transport, and duration of stay. Public parks play a very important part in the dayto-day lives of today's society and the environment. In Nairobi County, the parks are visited by both genders and are a source of places for relaxation. This implies that they are ideal for family and friends visits and as such, more should be created or the status is enhanced. Availability of free time for visiting the parks affects their usage, hence the influx of large numbers during weekends and public holidays. This calls for improved carrying capacity through expansions, redesign, and the creation of more parks. Other urban park uses include but is not limited to air purification, passive and active recreation, areas for physical and social activities. The study established that successful parks should offer a variety of activities, are safe, easily accessible, and serve visitors of different genders and ages groups. Moreover, proper design and good maintenance practices should always be embraced to ensure the sustainability of the parks.

\section{REFERENCES}

Babey, Susan \& Brown, E \& Hastert, T. (2006). Access to Safe parks helps increase physical activity among teenagers. Policy brief (UCLA Center for Health Policy Research). 1-6.

Baum, C. P. (2002). Opportunity structures: urban landscape, social capital and health promotion

in Australia. Health promotion international, 351-361. 
Beck, H. (2009). Linking the quality of public spaces to quality of life. Journal of Place Management and Development.

Cohen, D. A., Ashwood, J. S., Scott, M. M., Overton, A., Evenson, K. R., Staten, L. K., ... \& Catellier, D. (2006). Public parks and physical activity among adolescent girls. Pediatrics, 118(5), e1381-e1389.

Coles, R. W., \& Bussey, S. C. (2000). Urban forest landscapes in the UK-progressing the social agenda. Landscape and urban planning, 52(23), 181-188.

Deister, L. (2013). Designing Landscape as Infrastructure Water senstive open space design in Cairo. Cairo: Ain Shams University.

Gravin, R., McCormack, Rock, M., Toohey, A. M., \& Hignell, D. (2010). Characteristics of urban parks associated with park use and physical activity: A review of qualitative research. Health \& place, 16(4), 712-726.

Gehl, J. (1987). Life between buildings (Vol. 23). New York: Van Nostrand Reinhold.

Giles-Corti, B., Timperio, A., Bull, F., \& Pikora, T. (2005). Understanding physical activity environmental correlates: increased specificity for ecological models. Exercise and sport sciences reviews, 33(4), 175-181.

Grahn, P., \& Stigsdotter, U. A. (2003). Landscape planning and stress. Urban forestry \& urban greening, 2(1), 1-18.

Hayward, J. (1989). Urban parks. In public places and spaces (pp. 193-216). Springer, Boston, MA.

Kaplan, R. \& Matsuoka, R. H. (2008). People needs in the urban landscape: analysis of landscape and urban planning contributions. Landscape and urban planning, 84(1), 7-19.

Kellet, J. (2009). Creating active communities. South Australia: School of nature and built environment.

McCormack, G. R., Rock, M., Toohey, A. M., \& Hignell, D. (2010). Characteristics of urban parks associated with park use and physical activity: A review of qualitative research. Health \& place, 16(4), 712-726.

Mugenda O.M., and Mugenda, A. G. (2003). Research Methods. Quantitative \& Qualitative Approaches. Nairobi: Press African Center for Technology Studies (ACTS).

Ottensmann, J. R., \& Lindsey, G. (2008). A usebased measure of accessibility to linear features to predict urban trail use. Journal of Transport and Land Use, 1(1), 41-63.

Peters, K., Elands, B., \& Buijs, A. (2010). Social interactions in urban parks: Stimulating social cohesion? Urban forestry \& urban greening, 9(2), 93-100.

Saika U. \& Kikuchi T. (2017). Classification of Urban Parks and their Regional Characteristics in Dhaka City, Bangladesh. Journal of Environmental Science and Engineering $B 6$.

Solecki, W. D., \& Welch, J. M. (1995). Urban parks: green spaces or green walls? Landscape and urban planning, 32(2), 93-106.

Ulrich Roger, S., Simons Robert, F., Losito Barbara, D., \& Fiorito Evelyn, M. M. A. Zelson Michael, (1991). Stress Recovery During Exposure to Natural and Urban Environments. Journal of Environmental Psychology, 11, 201-230.

Van Herzele, A., \& Wiedemann, T. (2003). A monitoring tool for the provision of accessible and attractive urban green spaces. Landscape and urban planning, 63(2), 109-126.

Zhang, X., Lu, H., \& Holt, J. B. (2011). Modeling spatial accessibility to parks: a national study. International journal of health geographics, 10(1), 1-14. 